\title{
Análise de diversidade genética do gene da osteopontina em bovinos da raça girolando
}

\section{Fernanda de Mello ${ }^{1}$, Marta Fonseca Martins Guimarães ${ }^{2}$, Jaime Araújo Cobuci ${ }^{1}$, Marcos Vinícius Gualberto Barbosa da Silva ${ }^{2}$, José Braccini Neto ${ }^{1}$, Daisyléa de Souza Paiva ${ }^{3}$}

\author{
1 UFRGS, Porto Alegre, RS. \\ 2 Embrapa Gado de Leite, Juiz de Fora, MG. \\ 3 UFJF, Juiz de Fora, MG.
}

RESUMO - Objetivou-se obter os índices de diversidade genética para o SNP (single nucleotide polymorphism) do íntron 4 do gene da osteopontina (OPN) para 434 animais (87 touros e 347 vacas) participantes do Teste de Progênie da raça girolando no Brasil. Para a amplificação, foram utilizados primers descritos para a raça holandesa, e a diferenciação dos alelos C/T desse SNP foi obtida por meio da técnica de PCR-RFLP. As frequências genotípicas TT (52,53\%), CT (38,71\%) e CC (8,76\%) e as frequências alélicas de T (71,9\%) e C (28,1\%) indicam que a população encontra-se em Equilíbrio de Hardy-Weinberg (EHW). Apesar de o loco do gene $O P N$ estar em EHW, a frequência superior do alelo T do SNP nesses animais pode sugerir uma tendência de fixação do alelo $\mathrm{T}$ na raça. Não foi observada diferenciação entre o grupo de touros e vacas $\left(F_{S T}=-0,018\right)$, corroborando a estimativa de equilíbrio da população. Considerando os valores estimados pelo $F_{I S}(0,043)$, é possível que ocorram altos números de indivíduos homozigotos para o alelo $\mathrm{T}$ observados na população, em virtude da provável herança desse alelo vindo da raça zebuína, e não a endogamia. Assim, para melhor caracterização do polimorfismo do gene $O P N$, devem ser realizadas avaliações em maior número de animais, uma vez que só foram avaliados animais participantes do teste de progênie.

Palavras-chave: bovinos leiteiros, polimorfismo, produção de leite, SNP, SPP1

\section{Analysis of genetic diversity of osteopontin gene in girolando cattle}

\begin{abstract}
The objective was to obtain the indices of genetic diversity for the SNP (single nucleotide polymorphism) of the 4 intron osteopontin gene $(O P N)$ for 434 animals (87 bulls and 347 cows) participants in the Teste de Progênie da raça girolando (Girolando Progeny Test) in Brazil. For amplification, primers used were described for the Holstein breed, and differentiation of alleles C/T SNP that was obtained by PCR-RFLP. Genotype frequencies of TT (52.53\%), CT (38.71\%) and CC $(8.76 \%)$ and allele frequencies of $\mathrm{T}(71.9 \%)$ and $\mathrm{C}(28.1 \%)$ indicate that the population is in Hardy-Weinberg principle (HWP). Although the OPN gene locus is in HWP, the higher frequency of allele T of SNP in these animals may suggest a settingtrend of allele $\mathrm{T}$ in the race. No difference was observed between the group of bulls and cows $\left(F_{S T}=-0.018\right.$ ), supporting the estimate of population balance. Considering the values estimated by the $F_{I S}(0.043)$, it is likely that high numbers of individuals homozygous for the $\mathrm{T}$ allele observed in the population occur because of possible inheritance of this allele coming from the zebu breed, rather than inbreeding. Thus, to better characterize the $O P N$ gene polymorphism, assessments in a larger number of animals must be performed, since only animals that participated in the Progeny Test were assessed.
\end{abstract}

Key Words: dairy cattle, polymorphism, milk production, SNP, SPP1

\section{Introdução}

Animais da raça girolando destacam-se no cenário nacional por sua representatividade na produção de leite, pois são responsáveis por $80 \%$ da produção total no Brasil (ABCG, 2009). Estudos sobre a diversidade genética de raças sintéticas permitem aumentar a eficiência do processo de resposta seleção, assegurando a diversidade genética. Na diversidade genética, reside toda a capacidade de se promover seleção, e consequentemente melhoramento genético (Filho, 1999). A manutenção da diversidade é necessária para que os indivíduos se adaptem às mudanças, evitando a perda da diversidade alélica, que pode tornar a população mais suscetível a novas doenças e parasitoses, por exemplo. Além disso, a perda da heterozigosidade em populações selecionadas reduz a probabilidade de fixar genes favoráveis, diminuindo a resposta genética à seleção a médio e longo prazo (Cunha et al., 2004).

Estudos prévios identificaram o gene da osteopontina $(O P N)$ como candidato posicional para a produção de leite 
na raça holandesa (Zhang et al., 1998; Olsen et al., 2004). Esse gene, também conhecido como SPP1 (Secreted Phosphoprotein 1), apresenta expressão em diferentes tecidos, mas sua presença no leite e sua alta expressão nas células epiteliais da glândula mamária sugerem a importância dessa glicoproteína no desenvolvimento das características produtivas do leite (Nagatomo et al., 2004). Um polimorfismo de um único nucleotídeo (SNP) C/T no gene $O P N$ localizado no íntron 4 foi associado ao aumento nos percentuais de proteína e gordura no leite, sendo o alelo $\mathrm{C}$ responsável por efeito aditivo das características (Leonard et al., 2005). Khatib et al. (2007) confirmaram os resultados encontrados por Leonard et al. (2005) na raça holandesa, reforçando a importância desse gene na expressão destas características em bovinos leiteiros.

Para melhor entendimento da variabilidade genética e principalmente sua importância, é necessário conhecer a constituição genética da população (Filho, 1999). Avaliar animais da raça girolando para o polimorfismo do gene $O P N$ permite verificar como esse gene está distribuído na população e, futuramente, relacioná-lo com os registros produtivos visando a uma possível associação desse gene com a produção de leite. Assim, o objetivo neste trabalho consiste em investigar a diversidade genética do polimorfismo C/T do íntron 4 do gene $O P N$ em animais participantes do Teste de Progênie da raça girolando.

\section{Material e Métodos}

Para a obtenção dos dados genotípicos, foram coletadas amostras de sêmen de 87 touros da raça, representando a totalidade de reprodutores participantes do Teste de Progênie disponíveis até julho de 2009 e sangue de 347 vacas filhas desses animais. Todos os animais avaliados são participantes do Teste de Progênie da raça girolando coordenado Associação de Criadores da Raça Girolando em parceria com e Embrapa Gado de Leite, totalizando 434 animais avaliados. Os animais (touros e vacas) participantes deste trabalho são provenientes de diferentes propriedades distribuídas por diferentes localidades do Brasil, todas colaboradoras oficiais do Teste de Progênie da raça girolando.

O DNA genômico foi extraído das células do sangue e do sêmen utilizando-se o DNeasy Blood \& Tissue Kit (Qiagen, Valencia, CA, EUA), como recomendado pelo fabricante. O DNA total obtido foi quantificado por espectrofotometria (Nanodrop ${ }^{\circledR} 1000$, Thermo Fisher Scientific Inc., Wilmington, USA), e a relação $\mathrm{A}_{260} / \mathrm{A}_{280}$ utilizada para a avaliação da qualidade. O polimorfismo no gene OPN (GenBank NW_255516; GeneID: 281499) foi acessado por meio do SNP, localizado no íntron 4 desse gene por meio dos primers descritos por Leonard et al. (2005) e utilizando a técnica de PCR-RFLP para diferenciação dos alelos. A amplificação do DNA genômico foi realizada com o volume final de $25 \mu \mathrm{L}$ contendo 2 mmoles/ $\mathrm{L}$ de cada dNTP, 1X deGoTaq ${ }^{\circledR}$ Green Master Mix (Promega), 5 picomoles de cada primer e $70 \mathrm{ng}$ de DNA. As temperaturas e os ciclos para a amplificação foram os seguintes: um período inicial de desnaturação a $95^{\circ} \mathrm{C}$ por 5 minutos, seguido de 40 ciclos de amplificação de $95^{\circ} \mathrm{C}$ por $45 \mathrm{~s}, 50^{\circ} \mathrm{C}$ por $45 \mathrm{~s}, 72{ }^{\circ} \mathrm{C}$ por 45 s e um período adicional de polimerização a $72^{\circ} \mathrm{C}$ por 7 minutos. Para distinguir as duas formas variantes do SNP do gene $O P N, 15 \mu \mathrm{L}$ do produto da reação de PCR foram digeridos com 2,5 U da enzima de restrição Bsr I (New England Biolabs, Inc., Ipswich, EUA) em um volume final de $20 \mu \mathrm{L}$ incubados a $65^{\circ} \mathrm{C}$ por 3 horas, seguidos de um período de 20 min a $80^{\circ} \mathrm{C}$ para a inativação total da enzima. O produto da digestão foi analisado em gel de agarose 1,5\% para a detecção dos genótipos. O alelo $\mathrm{T}$ é identificado pela presença de uma banda não digerida de 290 pb, e o alelo C por uma banda digerida com $200 \mathrm{pb}$.

As medidas de diversidade genética na população para o gene da $O P N$ foram obtidas pela utilização do programa Genepop web version 4.0 (Rousset, 2008). A partir das frequências alélicas, foram obtidos os índices de diversidade genética da população. Com o objetivo de avaliar a variabilidade e o grau de estruturação da população, foram estimados os parâmetros $F_{I S}$ e $F_{S t}$, este último por meio da avaliação dos indivíduos dentro de cada sexo na população. O equilíbrio de Hardy-Weinberg (EHW) foi obtido por teste de probabilidade utilizando-se o método de cadeias de Markov mediante análise dos seguintes parâmetros: 2500 de desmemorização, 120 batches e 1000 permutações, por meio do programa Genepop (Rousset, 2008).

\section{Resultados e Discussão}

Foi obtida, como produto da amplificação do polimorfismo C/T do SNP no íntron 4 do gene OPN, uma banda de $290 \mathrm{pb}$, com dois alelos polimórficos representados por três fragmentos de 290, 200 e 90 pb, a partir da digestão enzimática do produto da PCR, sendo o alelo T identificado por uma banda não digerida de 290 pb, e o alelo C com duas bandas digeridas de 200 e 90 pb (Figura 1).

As frequências dos alelos T $(0,719)$ e C $(0,281)$ não estão igualmente distribuídas na população, tampouco as frequências genotípicas. Embora haja um número menor de heterozigotos observados, a população está em equilíbrio (Tabela 1). 


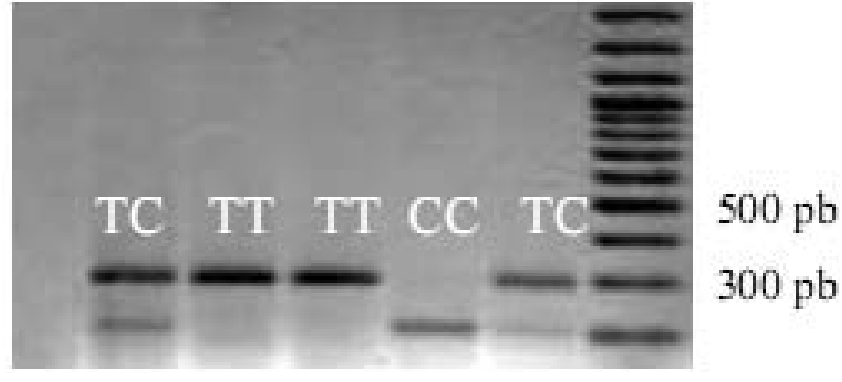

Figura 1 - Perfil genotípico do SNP C/T nos animais da raça girolando. Gel de agarose 1,5\%, marcador molecular de $100 \mathrm{pb}$.

Os resultados observados neste estudo estão de acordo com os encontrados por Pareek et al. (2008a), que constataram frequência superior do alelo T $(60,8 \%)$ em relação ao alelo C (39,2\%) em populações das raças leiteiras Polish Red e Polish Holstein, o que contrasta com a distribuição encontrada por Leonard et al. (2005) nas análises de populações leiteiras da raça holandesa, apresentando frequência de 49 e $51 \%$ para o alelo C e T, respectivamente. Khatib et al. (2007) observaram frequências genotípicas do gene $O P N$ de 26, 51 e 23\%, respectivamente, para os genótipos TT, CT e CC desse SNP divergindo das frequências genotípicas encontradas nos animais girolando, nos quais houve preponderância do alelo T.

De acordo com Belonsky \& Kenedy (1988), o fato de a seleção baseada no BLUP atribuir maior importância às informações da família aumenta o grau de homozigose, acentuando assim as perdas na diversidade genética.

As estimavas de heterozigosidade observada e esperada não diferiram, pois a população encontra-se em EHW $(\mathrm{P}>0,05)$. Em estudo para avaliar o SNP C/T do gene $O P N$ em raças de gado de corte dos EUA, no qual a seleção é direcionada para característica de crescimento e de ganho de peso, a frequência do alelo $\mathrm{T}$ foi superior ao do alelo C em animais jovens das raças Limousine $(60,4 \%)$ e Hereford (54,3\%), sugerindo a importância desse alelo no desenvolvimento das características corporais (Pareek et al., 2008a). Posteriormente, essa associação foi confirmada em famílias co-segregantes da raça holandesa da Polônia, onde foi detectado efeito significativo do alelo $\mathrm{T}$ do gene $O P N$ com o maior peso corporal em novilhas e touros jovens com 3, 6 e 12 meses de idade (Pareek et al., 2008b). O alelo C desse mesmo SNP (C/T) do gene $O P N$ foi associado ao aumento no percentual de gordura e proteína do leite em duas diferentes populações da raça holandesa (Leonard et al., 2005; Khatib et al., 2007).

A raça girolando historicamente foi selecionada para a produção de leite, uma vez que a correlação genética entre produção de leite e seus constituintes é negativa. Como o alelo C está associado ao percentual de gordura e proteína no leite na raça holandesa, são compreensíveis os resultados encontrados de baixa frequência para esse alelo. Um estudo realizado com zebuínos da raça Nelore mostrou a ausência do alelo C na população analisada, sugerindo que a presença do alelo T é uma característica de Bos taurus indicus, mas não foi descartada a hipótese de seleção indireta nesse loco (Souza, 2007).

O método de avaliação utilizado na raça girolando favorece indivíduos dentro de uma mesma família e, consequentemente, pode aumentar o nível de homozigose na população, além de diminuir a variabilidade. Certo grau de endogamia é aparentemente inevitável, pois determinados indivíduos selecionados são utilizados de maneira intensa, provocando o acasalamento de indivíduos com algum grau de parentesco maior que aquele que ocorreria em estrutura totalmente aleatória de acasalamento (Filho, 1999). O parâmetro $F_{I S}$ é uma medida que indica correlação de genes de cada indivíduo dentro da sua população e indica o desvio de heterozigosidade entre os indivíduos em relação a sua população, enquanto o $F_{S t}$ indica se existe diferenciação populacional (Weir \& Cockerman, 1984). O parâmetro $F_{I S}(0,043)$ é comparável a estimativa do $f$ de Wright (1931) (Weir \& Cockerman, 1984), portanto, com as baixas estimativas de endogamia encontradas, a população analisada possivelmente apresenta maior número de indivíduos homozigotos para o alelo $\mathrm{T}$ em função de esse alelo ser herdado da raça zebuína, e não devido à endogamia. Como o loco encontra-se em equilíbrio e não sofre pressão

Tabela 1 - Índices de diversidade genética na população da raça girolando para o polimorfismo C/T do íntron 4 do gene da osteopontina

\begin{tabular}{|c|c|c|c|c|c|c|}
\hline \multirow[t]{2}{*}{ Genótipo } & \multicolumn{2}{|c|}{ Frequência genotípica (\%) } & \multirow[t]{2}{*}{ Frequência alélica } & \multirow[t]{2}{*}{ E-HW(p-valor) } & \multirow[t]{2}{*}{$F_{I S}$} & \multirow[t]{2}{*}{$F_{S T}$} \\
\hline & Observada & Esperada & & & & \\
\hline $\mathrm{CC}$ & 8,76 & 7,88 & 28,1 & & & \\
\hline $\mathrm{CT}$ & 38,71 & 40,46 & & $0,4061 *$ & 0,043 & $-0,018$ \\
\hline $\mathrm{T} \mathrm{T}$ & 52,53 & 51,66 & 71,9 & & & \\
\hline
\end{tabular}

* $\mathrm{P}>0,05$

EHW = equilíbrio de Hardy-Weinberg.

Estatísticas $\mathrm{F}\left(F_{I S}\right.$ e $\left.F_{S T}\right)$. 
de seleção diretamente, essa hipótese reforçaria os resultados encontrados por Souza (2007) de que o alelo T é característico de Bos taurus indicus. Analisar o parâmetro $F_{S t}$ é importante para se avaliar a diferenciação entre touros e vacas, tendo em vista que os touros sofrem maior pressão e intensidade de seleção dentro do rebanho.

Não foi observada diferenciação entre o grupo de touros e vacas $\left(F_{S T}=-0,018\right)$, corroborando a estimativa de equilíbrio para esse loco na população. Futuras avaliações do polimorfismo no gene $O P N$ em maior número de animais da raça girolando devem ser realizados, uma vez que só foram avaliados animais participantes do Teste de Progênie.

\section{Conclusões}

Os animais avaliados, participantes do Teste de Progênie da raça girolando, encontram-se em EHW para o loco do SNP do íntron 4 do gene $O P N$. Apesar disso, é maior a frequência do alelo $\mathrm{T}$ desse SNP nos animais avaliados.

\section{Referências}

ASSOCIAÇÃO BRASILEIRA DE CRIADORES DE GIROLANDO - ABCG. [2009]. Girolando - A raça mais versátil do mundo tropical. Disponível em: <http://www.girolando.com.br/ site/ogirolando/performance.php> Acesso em: 19 mar. 2009.

BELONSKY, G.M.; KENNEDY, J.L. Selection on individual phenotype and best linear unbiased predictor of breeding value in a closed swine herd. Journal of Animal Science, v.66, p.1164-1181, 1988.

CUNHA, E.E.; EUCLYDES, R.F.; TORRES, R.A. Variabilidade genética e limite da seleção em populações de diferentes tipos de acasalamento. Arquivo Brasileiro de Medicina Veterinária e Zootecnia, v.56, n.2, p.242-250, 2004.
FILHO, E.K. Melhoramento genético animal no Brasil. Fundamentos, história e importância. Campo Grande: Embrapa, 1999. 63p.

KHATIB, H.; ZAITOUN, I.; WIEBELHAUS-FINGER, J. et al. The Association of Bovine PPARGC1A and OPN Genes with Milk Composition in Two Independent Holstein Cattle Populations. Journal of Dairy Science, v.90, p.2966-2970, 2007.

LEONARD, S.; KHATIB, H.; SCHUTZKUS, V. et al. Effects of the osteopontin gene variants on milk production traits in dairy cattle. Journal of Dairy Science, v.88, p.4083-4086, 2005.

NAGATOMO, T.; OHGA, S.; TAKADA, H. et al. Microarray analysis of human milk cells: persistent high expression of osteopontin during the lactation period. Clinical and Experimental Immunology, v.138, p.47-53, 2004.

OLSEN, H.G.; LIEN, S.; SVENDSEN, M. et al. Fine mapping of milk production QTL on BTA6 by combined linkage and linkage disequilibrium analysis. Journal of Dairy Science, v.87, p.690-698, 2004.

PAREEK, C.S.; ZIÊBA, M.; MICHNO, J. et al. Study of SNP C>T polymorphism within the candidate genes for dairy and beef traits in a panel of selected cattle breeds. Journal of Agrobiology, v.25, n.1, p.121-124, 2008a.

PAREEK, C.S.; CZARNIK, U.; PIERZCHA£A, M. et al. An association between the $\mathrm{C}>\mathrm{T}$ single nucleotide polymorphism within íntron IV of osteopontin encoding gene (SPP1) and body weight of growing Polish Holstein-Friesian cattle. Animal Science Papers and Reports, v.26, n.4, p.251-257, 2008b.

ROUSSET, F. [2008] Genepop'007: a complete reimplementation of the Genepop software for Windows and Linux. Molecular Ecology Resources, v.8, p.103-106, 2008. Disponível em: $<$ http://genepop.curtin.edu.au/> Acesso em: 25 set. 2009.

SOUZA, F.R.P. Polimorfismo dos genes MUC1 e Osteopontina em novilhas da raça Nelore (Bos taurus indicus). 2007. 96f. Tese (Doutorado em Ciências Biológicas) - Faculdade de Medicina de Ribeirão Preto/Universidade de São Paulo, Ribeirão Preto.

WEIR, B.S.; COCKERHAM, C.C. Estimating F-statistics for the analysis of population structure. Evolution, v.38, p.1358-1370, 1984.

WRIGHT, S. Evolution in Mendelian populations. Genetics, v.16, p.97-159, 1931

ZHANG, Q.; BOICHARD, D.; HOESCHELE, I. et al. Mapping quantitative trait loci for milk production and health of dairy cattle in a large outbred pedigree. Genetics, v.149, p.1959-1973, 1998. 